\title{
The Inhibition of Carbon Steel Corrosion in Hydrochloric Acid Media Using 2-[(5-methyl-isoxazol-3-yl)-methyl]-benzimidazole
}

\author{
J. Sebhaoui ${ }^{1}$, Y. El Aoufir ${ }^{2,3}$, Y. El Bakri' ${ }^{1,2}$, H. Bourazmi ${ }^{4}$, A. Ben Ali5, \\ A. Guenbour ${ }^{4}$, H. Oudda ${ }^{3}$, A. Zarrouk ${ }^{1,4, *}$ and E.M. Essassi ${ }^{1, *}$ \\ ${ }^{1}$ Laboratory of Heterocyclic Organic Chemestry, URAC 21, Pole of Competence, \\ Pharmacochemics, Av IbnBattouta, P.O. 1014, Faculty of Sciences, \\ University Mohammed V, Rabat, Maroc \\ ${ }^{2}$ Department of Chemistry, Peoples' Friendship University of Russia (RUDN University), \\ 6 Miklukho-Maklaya st., Moscow, 117198, Russian Federation. \\ ${ }^{3}$ Laboratory of Separation Processes, University Ibn Tofail, Faculty of Sciences, \\ Kenitra, Morocco \\ ${ }^{4}$ Laboratory of Materials, Nanotechnology and Environment, Mohammed V University, \\ Faculty of Sciences, Av. ibn Battuta. B.P 1014, Rabat, Morocco \\ ${ }^{5}$ Laboratory of Applied Chemestry of Materials, Centres for Sciences of Materials, Faculty of \\ Sciences, Mohammed V University in Rabat, Avenue Ibn Battouta, P.O. 1014, Rabat, Morocco \\ *Corresponding author: azarrouk@gmail.com
}

Received 25/06/2018; accepted 15/09/2020

https://doi.org/10.4152/pea.2021390305

\begin{abstract}
Carbon steel corrosion inhibition in a hydrochloric acid solution by 2-[(5-methylisoxazol-3-yl)-methyl]-benzimidazole (MMB) has been studied by electrochemical techniques (PDP and EIS). Results showed that the inhibition efficiency increases with higher $\mathrm{MMB}$ concentration, and the maximum value of $86.6 \%$ was obtained at $10^{-3} \mathrm{M}$ concentration. The prepared benzimidazole inhibitor showed higher inhibition efficiency upon raising the solution temperature from 303 to $333 \mathrm{~K}$. Corrosion current density decreased from $660.9 \mu \mathrm{A} \mathrm{cm}^{-2}$ (blank) to $97.8 \mu \mathrm{A} \mathrm{cm}{ }^{-2}$ (MMB) and charge transfer resistance increased from $20.2 \Omega \mathrm{cm}^{2}$ (blank) to $150.8 \Omega \mathrm{cm}^{2}$ (MMB). PDP studies showed that MMB is a mixed type inhibitor. The adsorption of this compound onto the carbon steel surface in a $1 \mathrm{M} \mathrm{HCl}$ solution followed the Langmuir adsorption isotherm, and the value of the standard free energy of adsorption $\left(\Delta G_{a d s}^{\circ}\right)$ is associated to physisorption and chemisorption.
\end{abstract}

Keywords: carbon steel, corrosion inhibition, Benzimidazole, electrochemical techniques.

\section{Introduction}

Carbon steel is widely used in various industries, such as oil and gas exploration and production, petroleum refining, chemical manufacturing, water treatment, and in the product additive industries that play an important role in the economy $[1,2]$. Acidic solutions employed in these industries lead to corrosion attack on the mild steel, which in turn generates a great loss [3]. The use of organic inhibitors is one 
of the most practical methods for metals protection against corrosion. The organic molecules have the strongest adsorption ability on metal surfaces, which can markedly increase their inhibitory efficiency and change the corrosion resisting properties of metals $[4,5]$. The inhibitory effect depends mainly on the nature and the surface charge of metals, on the chemical structure of organic molecules such as functional groups, steric factors, electron density, etc., and on the type of solution [6-9]. The existing data in literature show that organic compounds having heteroatoms with high electron density, such as phosphorus, sulfur, nitrogen, oxygen or those containing multiple bonds, are effective inhibitors for metal corrosion [5-14]. The objective of this study is the use of chemicals compounds with low or no environmental impacts at low dosages [15-17]. On this content, we have recently focused on the inhibitory efficiencies of benzimidazole derivatives which are not toxic. 2-[(5-Methyl-isoxazol-3-yl)-methyl]benzimidazole (MMB) molecule contains many $\pi$ - electrons, as well as one oxygen atom and three nitrogen atoms. The tested inhibitor has a molecular structure providing greater adsorption ability onto the carbon steel surface and high inhibitory efficiency. Due to the advantage of the organic compounds, which are described above, further detailed studies on the mechanism and stability of the inhibitor film on the metal surface would benefit contributions to its usage for practical applications. The aim of the present study is to investigate the adsorption and corrosion inhibition mechanism of $\mathrm{MMB}$ on carbon steel in a $1 \mathrm{M} \mathrm{HCl}$ solution. For this aim, potentiodynamic polarization and electrochemical impedance spectroscopy (EIS) techniques were used. The inhibitor molecule used in this paper has the structure presented in Fig. 1.

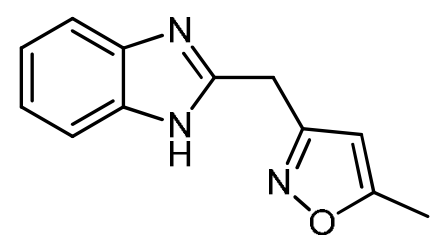

Figure 1. The chemical structure of the investigated organic compound.

\section{Experimental details}

\section{Inhibitor synthesis}

Benzimidazole and its derivatives are an important class of bioactive molecules. We have redone the reaction of Azzaoui and al. [18], who have obtained the isoxazolyl-methylbenzimidazole 1 from the action of hydroxylamine hydrochloride on 4Z-(2-oxopropylidene)-2,3,4,5-tetrahydro-1 H-1,5-benzodiazepin-2-one 1 (Scheme 1).

To a solution of 4Z-(2-oxopropylidene)-1,2,4,5-tetrahydro-1H-1,5-benzodiazepin2-one 1 (10 mmol) in ethanol, it was added hydroxylamine hydrochloride (10 mmol) and all was refluxed for a period of $2 \mathrm{~h}$. After neutralization with $\mathrm{NaHCO}_{3}$, the formed residue was recrystallized from ethyl acetate to afford the title compound $\underline{2}$ as colorless crystals. The compound is characterized by ${ }^{1} \mathrm{H}-\mathrm{NMR}$ 
(DMSO-d 6$): 2.36\left(\mathrm{~s}, 3 \mathrm{H}, \mathrm{CH}_{3}\right), 4.26\left(\mathrm{~s}, 2 \mathrm{H}, \mathrm{CH}_{2}\right), 6.23(\mathrm{~s}, 1 \mathrm{H})$ and $7.00-7.60$ (m, $\mathrm{CH}_{\text {aromatique }) \text {. }}$

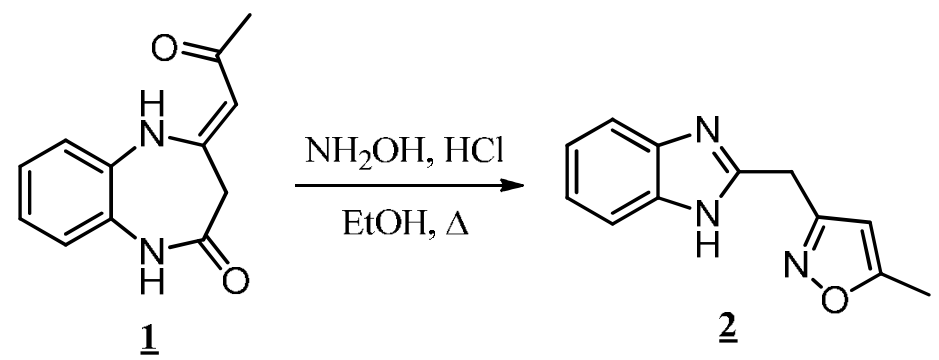

Scheme 1. Synthesis of 2-[(5-methyl-isoxazol-3-yl)-methyl]-benzimidazole.

\section{Preparation of electrodes and test solution}

Corrosive solutions were prepared by dilution of a $37 \% \mathrm{HCl}$ analytical reagent grade with doubly distilled water. The tested concentrations ranged from $10^{-3}$ to $10^{-6}$ M. Steel strips contained 0.36 wt.\% C, 0.66 wt. $\%$ Mn, 0.27 wt. $\% \mathrm{Si}, 0.02$ wt. $\%$ S, 0.015 wt. $\%$ P, 0.21 wt. $\%$ Cr, 0.02 wt. $\%$ Mo, 0.22 wt. $\%$ Cu, 0.06 wt.\% Al and the remainder iron.

The working area of $1 \mathrm{~cm}^{2}$ was subsequently ground with 200 and 1200 grit grinding papers, cleaned by distilled water and ethanol at hot air. The effect of temperature on the inhibition efficiencies of the inhibitor was tested from 303 to $333 \mathrm{~K}$.

\section{Electrochemical experiments}

The effect of 2-[(5-methyl-isoxazol-3-yl)-methyl]-benzimidazole (MMB) on the carbon steel corrosion was studied using electrochemical techniques: electrochemical impedance spectroscopy (EIS) and polarization potentiodynamic (PDP), in the concentration range of $10^{-3}$ to $10^{-6} \mathrm{M}$, at $303 \mathrm{~K}$.

The electrochemical experiment consisted of a three electrode electrolytic cell made by a platinum foil as counter electrode, saturated calomel as reference electrode and carbon steel as working electrode, with an exposed area of $1 \mathrm{~cm}^{2}$.

The carbon steel specimen was immersed in a test solution for $30 \mathrm{~min}$, until a steady-state (open circuit) potential was achieved using a type PGZ100 potentiostat. EIS measurements were performed with a frequency range from 100 $\mathrm{KHz}$ to $10 \mathrm{mHz}$ and an amplitude of $10 \mathrm{mV}$ with 10 points per decade.

The polarization curves were recorded by polarization from -600 to $-200 \mathrm{mV} / \mathrm{SCE}$, with a scan rate of $0.5 \mathrm{mV} / \mathrm{s}$.

The data obtained by PDP and EIS methods were analyzed and fitted using graphing and analyzing impedance software, version EcLab. 


\section{Results and discussion}

\section{Effect of inhibitor concentration}

Potentiodynamic polarization curves

Fig. 2 present the polarization curves for carbon steel in a $1 \mathrm{M} \mathrm{HCl}$ solution and in the presence of our compound tested at $303 \mathrm{~K}$. Table 1 regroups the parameters derived from PDP plots. The values of $\eta_{\mathrm{PDP}}(\%)$ are calculated by the following formula:

$$
\eta_{P D P}(\%)=\frac{i_{c o r r}^{\circ}-i_{c o r r}^{i}}{i_{c o r r}^{\circ}} \times 100
$$

where $i_{\text {corr }}^{\circ}$ and $i_{\text {corr }}^{i}$ are the corrosion current densities in uninhibited and inhibited media, respectively.

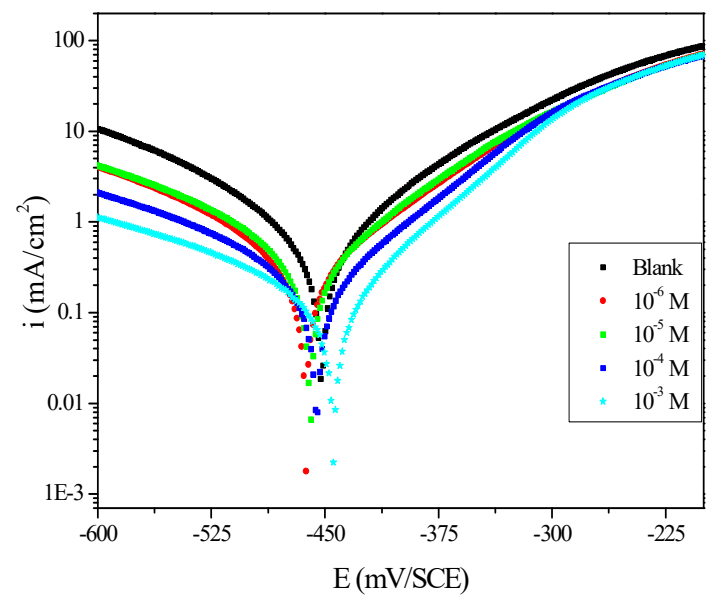

Figure 2. Potentiodynamic polarization curves for carbon steel in the absence and presence of different MMB concentrations.

Table 1. Tafel polarization parameters for carbon steel in a $1 \mathrm{M} \mathrm{HCl}$ solution, in the absence and at different concentrations of MMB at $303 \mathrm{~K}$.

\begin{tabular}{lllllll}
\hline Medium & $\begin{array}{l}\text { Conc } \\
(\mathbf{M})\end{array}$ & $\begin{array}{l}-\mathbf{E}_{\text {corr }} \\
(\mathbf{m V} / \mathbf{S C E})\end{array}$ & $\begin{array}{l}\mathbf{i}_{\text {corr }} \\
\left(\boldsymbol{\mu} \mathbf{A} \mathbf{~ c m}^{-2}\right)\end{array}$ & $\begin{array}{l}\boldsymbol{\beta}_{\mathbf{a}} \\
\left(\mathbf{m V} \mathbf{d e c}^{-\mathbf{1}}\right)\end{array}$ & $\begin{array}{l}-\boldsymbol{\beta}_{\mathbf{c}} \\
(\mathbf{m V ~ d e c}\end{array}$ & $\begin{array}{l}\boldsymbol{\eta}_{\mathbf{P D P}} \\
(\mathbf{\%})\end{array}$ \\
\hline Blank & 1 & 452.2 & 660.9 & 95.3 & 113.0 & - \\
& & & & & & \\
& $10^{-6}$ & 462.3 & 236.8 & 82.7 & 87.0 & 64.2 \\
\multirow{2}{*}{ MMB } & $10^{-5}$ & 459.6 & 225.7 & 72.8 & 79.9 & 65.8 \\
& $10^{-4}$ & 456.0 & 149.8 & 74.3 & 95.2 & 77.3 \\
& $10^{-3}$ & 444.9 & 97.8 & 66.8 & 112.4 & 85.2 \\
\hline
\end{tabular}

Analysis of the PDP curves indicates that the addition of MMB decreases both cathodic and anodic current densities with the increase in the inhibitor concentration. The presence of the inhibitor tested in the aggressive medium causes a slight change in the shift of $\mathrm{E}_{\text {corr }}$ values in all tested concentrations, suggesting that $\mathrm{MMB}$ can be classified as a mixed type inhibitor [19], with no change in the metal corrosion mechanism [20]. 
Table 1 shows that the corrosion current densities ( $\mathrm{i}_{\text {corr }}$ ) decrease when the MMB concentration rises in the acidic solution, reaching a value of $97.8 \mu \mathrm{A} / \mathrm{cm}^{2}$ at an inhibitor concentration of $10^{-3} \mathrm{M}$. This $i_{\text {corr }}$ value led to an $\eta_{\mathrm{PDP}} \%$ of about $85.2 \%$ and confirms that MMB is a good inhibitor against carbon steel corrosion in a $\mathrm{HCl}$ medium. A slight variation in the values of anodic and cathodic Tafel slopes is observed with the inhibitor presence. These results suggest that the surface blocking effect of the tested adsorbed compound diminishes the anodic and cathodic reactions [21].

\section{Electrochemical impedance spectroscopy measurements}

Impedance method provides information about the kinetics of the electrode processes and, simultaneously, about the surface properties of the investigated systems. So, the protective effectiveness of MMB on the carbon steel corrosion in the acidic medium $(1 \mathrm{M} \mathrm{HCl})$ was studied by EIS method at $303 \mathrm{~K}$, after $30 \mathrm{~min}$ of immersion. Fig. 3 shows the influence of MMB concentrations on Nyquist impedance spectra.

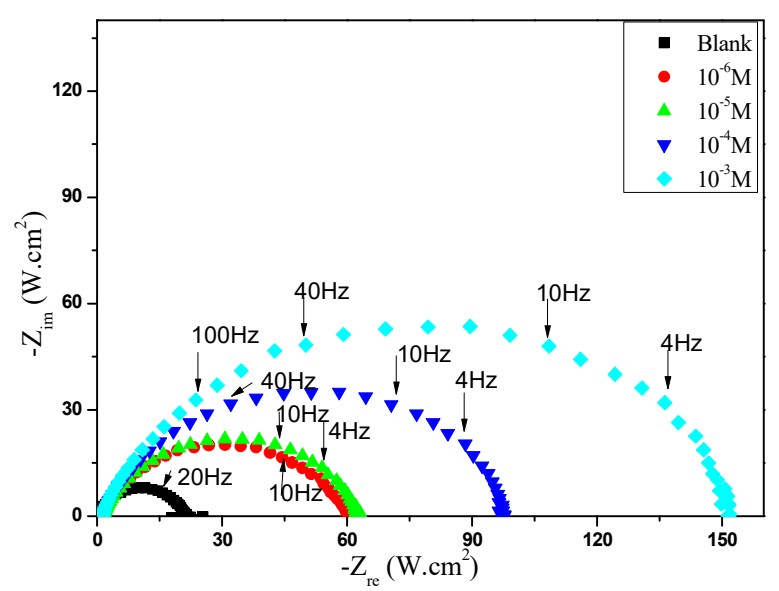

Figure 3. Nyquist plot for carbon steel in $1 \mathrm{M} \mathrm{HCl}$, in the absence and presence of different concentrations of MMB at $303 \mathrm{~K}$.

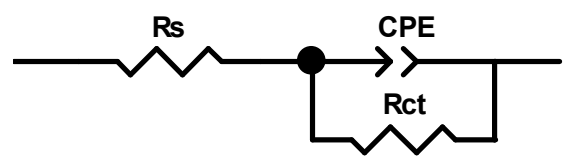

Figure 4. The equivalent circuit model used to fit the EIS data.

This figure shows that only single semicircles are observed with the depression at a low frequency, in MMB presence and absence. This depression is probably due to the inhomogeneity and roughness of the carbon steel surface [24]. A remarkable increase in the semicircle diameter is observed when the concentration of MMB rises; this behavior is the result of the inhibitor adsorption onto the carbon steel surface [25]. The equivalent circuit model shown in Fig. 4 was used to analyze the EIS experiments.Various impedance parameters, namely solution resistance $\left(\mathrm{R}_{\mathrm{s}}\right)$, charge transfer resistance $\left(\mathrm{R}_{\mathrm{ct}}\right)$, double layer capacitance $\left(\mathrm{C}_{\mathrm{dl}}\right)$, inhibition 
efficiency $\left(\eta_{\mathrm{z}} \%\right)$ and surface coverage $(\theta)$ were calculated using the equivalent circuit model shown in Fig. 4 and given in Table 2.

Table 2. Electrochemical impedance spectroscopy parameters obtained for carbon steel in a $1 \mathrm{M} \mathrm{HCl}$ solution, in the absence and at different concentrations of MMB at $303 \mathrm{~K}$.

\begin{tabular}{|c|c|c|c|c|c|c|c|c|}
\hline Medium & $\begin{array}{l}\text { Conc. } \\
(\mathrm{M})\end{array}$ & $\begin{array}{l}R_{s} \\
\left(\Omega \mathrm{cm}^{2}\right)\end{array}$ & $\begin{array}{l}\mathbf{R}_{\mathrm{ct}} \\
\left(\Omega \mathrm{cm}^{2}\right)\end{array}$ & $\begin{array}{l}10^{-4} \times Q \\
\left(\Omega^{-1} \mathrm{~cm}^{-2} s^{-n}\right)\end{array}$ & $\mathbf{n}$ & $\begin{array}{l}C_{d l} \\
\left(\mu \mathrm{F} \mathrm{cm}^{-2}\right)\end{array}$ & $\boldsymbol{\theta}$ & $\begin{array}{l}\eta_{z} \\
(\%)\end{array}$ \\
\hline \multirow[t]{2}{*}{ Blank } & 1 & 0.57 & 20.2 & 2.42 & 0.860 & 112.0 & - & - \\
\hline & $10^{-6}$ & 1.32 & 58.9 & 1.98 & 0.778 & 56.1 & 0.656 & 65.6 \\
\hline \multirow[t]{3}{*}{ MMB } & $10^{-5}$ & 1.38 & 61.1 & 1.90 & 0.782 & 54.8 & 0.669 & 66.9 \\
\hline & $10^{-4}$ & 1.37 & 97.6 & 1.36 & 0.792 & 44.4 & 0.793 & 79.3 \\
\hline & $10^{-3}$ & 1.17 & 150.8 & 1.07 & 0.790 & 35.7 & 0.866 & 86.6 \\
\hline
\end{tabular}

The inhibiting efficiency derived from EIS, $\eta_{z}(\%)$, was calculated by the following equation:

$$
\eta_{z}(\%)=\frac{R_{c t}^{i}-R_{c t}^{\circ}}{R_{c t}^{i}} \times 100
$$

where $R_{c t}^{\circ}$ and $R_{c t}^{i}$ are the charge transfer resistance, in the inhibitor absence and presence, respectively.

The double layer capacitance $\left(\mathrm{C}_{\mathrm{dl}}\right)$ values are calculated using Eq. (3):

$$
C_{d l}=\sqrt[n]{Q \times R_{c t}^{1-n}}
$$

where $\mathrm{Q}$ is the CPE constant and $\mathrm{n}$ is a coefficient that can be used as a measure of surface inhomogeneity [26].

From Table 2, it can be observed that $R_{c t}$ value increases with a higher concentration of $\mathrm{MMB}$, while the $\mathrm{C}_{\mathrm{dl}}$ values decreases. These results demonstrate that the compound was adsorbed onto the carbon steel surface by the formation of a protective film at the metal/solution interface [27-29].

The $C_{\mathrm{dl}}$ values diminished with the increase in the MMB concentration. The effect of the dielectric constant of a material on the interface capacitance can be related to the following equation:

$$
C=\frac{\varepsilon \varepsilon_{0}}{\delta}
$$

where $\delta$ is the film thickness, $\varepsilon$ the material dielectric constant and $\varepsilon_{0}$ is the vacuum permittivity $\left(8.8542 \times 10^{-14} \mathrm{~F} \mathrm{~cm}^{-1}\right)$. Based on the aforementioned, the increase in the MMB concentration reduces the interface dielectric effect. This behavior is due to a substitution process of adsorbed water molecules by MMB molecules, because their dielectric constants are lower than those of water. In this way, a protective film is formed, which diminishes the active sites on the steel surface and, consequently, the rate of the electrochemical corrosion reactions. The $\eta_{\mathrm{z}} \%$ values obtained in the EIS study were in good agreement with those calculated in PDP studies. 


\section{Adsorption isotherms}

The inhibition efficiency of the corrosion inhibitor mainly depends on the interaction between inhibitor and metal surface, and it can be provided by the adsorption isotherm [30]. In order to evaluate MMB adsorption process in a carbon steel surface, Langmuir, Temkin, Freundlich and Frumkin adsorption isotherms were tested.

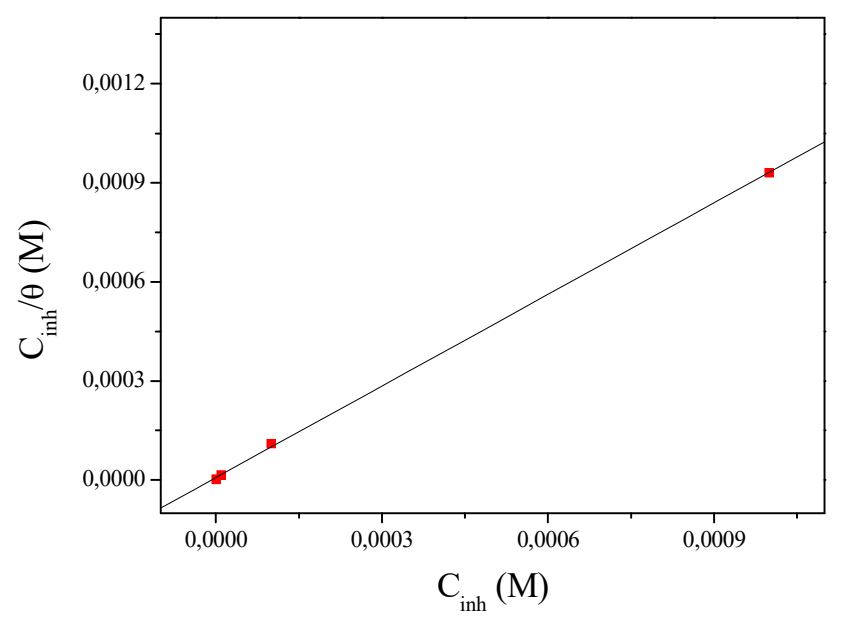

Figure 5. Plots of the Langmuir adsorption isotherm of the MMB on the carbon steel surface at $303 \mathrm{~K}$.

A plot of $C_{\text {inh }} / \theta$ versus $C_{\text {inh }}$ (Fig. 5) was found to be the best fit, which suggests that MMB adsorption onto the carbon steel surface in the tested medium obeys the Langmuir adsorption. The Langmuir isotherm can be best expressed by the following relation (5):

$$
\frac{C_{i n h}}{\theta}=\frac{1}{K_{a d s}}+C_{i n h}
$$

where $\mathrm{C}_{\mathrm{inh}}$ is the $\mathrm{MMB}$ concentration and $\mathrm{K}_{\mathrm{ads}}$ is the equilibrium constant for the adsorption-desorption process [31]. From the intercept of the straight lines in Langmuir plot, the value of the $\mathrm{K}_{\mathrm{ads}}$ is calculated and given in Table 3. This value is also related to the standard free energy of adsorption, $\Delta G_{a d s}^{\circ}$, by the following equation $6[32,33]$ :

$$
\Delta G_{a d s}^{\circ}=-R T \operatorname{Ln}\left(55.5 K_{a d s}\right)
$$

where the constant of 55.5 is the concentration of water in solution mol dm $\mathrm{dm}^{-3}, \mathrm{R}$ is the gas constant and $\mathrm{T}$ is the absolute temperature. The parameters of adsorption are regrouped in Table 3 .

Table 3. Adsorption parameters for carbon steel corrosion in $1 \mathrm{M} \mathrm{HCl}$ at $303 \mathrm{~K}$.

\begin{tabular}{llllc}
\hline Inhibitor & $\begin{array}{l}\text { Kads } \\
\left(\mathbf{M}^{-1}\right)\end{array}$ & $\begin{array}{l}-\Delta \mathbf{G}^{\circ} \text { ads } \\
\left(\mathbf{K J ~ m o l}^{-\mathbf{1}}\right)\end{array}$ & $\mathbf{R}^{\mathbf{2}}$ & Slope \\
\hline MMB & $1.323668 \times 10^{5}$ & 39.82 & 0.9997 & 1.1 \\
\hline
\end{tabular}


The high $\mathrm{K}_{\mathrm{ads}}$ value obtained in this study indicates the strong interaction between the carbon steel surface and MMB adsorbing molecules [20]. The calculated value of $\Delta G_{a d s}^{\circ}$ is around $39.82 \mathrm{~kJ} / \mathrm{mol}$, suggesting that the adsorption mechanism of MMB onto carbon steel in $1 \mathrm{M} \mathrm{HCl}$ is probably of a mixed type adsorption: physisorption and chemisorption [34].

\section{Effect of temperature}

The effect of temperature on the corrosion inhibition was studied using PDP measurement, in the temperature range from 303 to $333 \mathrm{~K}$, without and with $10^{-3}$ $\mathrm{M}$ of MMB during $0.5 \mathrm{~h}$ of immersion. The electrochemical parameter extracted by PDP method, included in Table 4 and Fig. 6 ( $a$ and b), shows an increase in $\mathrm{i}_{\text {corr }}$ with an increase in temperature, and it is more pronounced for the uninhibited solution. We observe that the inhibitor efficiency decreased with a rise in temperature, suggesting that the higher temperature does influence the inhibitor adsorption onto the metal surface.
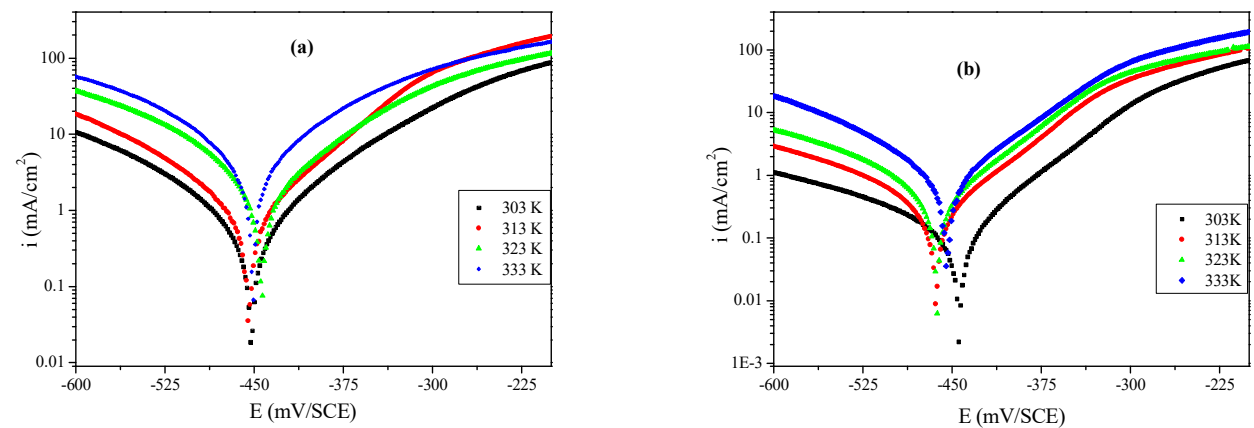

Figure 6. Effect of temperature on the behavior of carbon steel/ $1 \mathrm{M} \mathrm{HCl}$ interface in (a) uninhibited solution and (b) at $10^{-3} \mathrm{M}$ of MMB.

Table 4. Temperature influence on the PDP parameters for carbon steel in $1 \mathrm{M} \mathrm{HCl}$, with and without $\mathrm{HCl}(1 \mathrm{M})+10^{-3} \mathrm{M}$ of $\mathrm{MMB}$, at a temperature range from $303 \mathrm{~K}$ to $333 \mathrm{~K}$.

\begin{tabular}{|c|c|c|c|c|c|c|}
\hline Medium & $\begin{array}{l}\text { Temp } \\
\text { (K) }\end{array}$ & $\begin{array}{l}-E_{\text {corr }} \\
(\mathrm{mV} / \mathrm{SCE})\end{array}$ & $\begin{array}{l}\mathbf{i}_{\text {corr }} \\
\left(\mu \mathrm{A} \mathrm{cm^{-2 }}\right)\end{array}$ & $\begin{array}{l}\beta_{\mathrm{a}} \\
\left(\mathrm{mV} \operatorname{dec}^{-1}\right)\end{array}$ & $\begin{array}{l}-\beta_{\mathrm{c}} \\
\left.(\mathrm{mV} \mathrm{dec})^{-1}\right)\end{array}$ & $\begin{array}{l}\text { ПPDP } \\
(\%)\end{array}$ \\
\hline \multirow{4}{*}{ Blank } & 303 & 452.2 & 660 & 95.3 & 113.0 & - \\
\hline & 313 & 454.5 & 865 & 79.1 & 95.4 & - \\
\hline & 323 & 443.4 & 1529 & 88.7 & 79.3 & - \\
\hline & 333 & 450.8 & 2898 & 82.8 & 82.9 & - \\
\hline \multirow{4}{*}{ MMB } & 303 & 444.9 & 98 & 66.8 & 112.4 & 85.2 \\
\hline & 313 & 463.4 & 225 & 72.2 & 96.0 & 74.0 \\
\hline & 323 & 462.1 & 453 & 75.3 & 108.3 & 70.4 \\
\hline & 333 & 454.6 & 1007 & 82.9 & 105.9 & 65.2 \\
\hline
\end{tabular}

The effect of temperature on the corrosion current $\left(i_{\text {corr }}\right)$ can be used for determining the activation thermodynamic parameters for the dissolution process, following the Arrhenius equation (Eq.7) and transition state equation (Eq.8) $[35,36]$ :

$$
\operatorname{Lni} i_{c o r r}=\operatorname{Ln} A+\left(\frac{-E_{a}}{R T}\right)
$$




$$
i_{\text {corr }}=\frac{R T}{N h} \exp \left(\frac{\Delta S_{a}}{R}\right)\left(\frac{-\Delta H_{a}}{R T}\right)
$$

where $\mathrm{E}_{\mathrm{a}}$ is the activation corrosion energy, $\Delta \mathrm{H}_{\mathrm{a}}$ is the enthalpy, $\Delta \mathrm{S}_{\mathrm{a}}$ is the entropy of activation, $\mathrm{T}$ is the absolute temperature in Kelvin, $\mathrm{h}$ is the Plank constant, $\mathrm{N}$ is the Avogadro number and $\mathrm{R}$ is the molar gas constant. Arrhenius plots for the corrosion rate of carbon steel are given in Fig. 7. Using the slope of Ln ( $\left.i_{\text {corr }}\right)$ vs. $1 / \mathrm{T}$ plots, the values of the apparent activation energy of corrosion $\left(\mathrm{E}_{\mathrm{a}}\right)$ have been determined (Table 5).

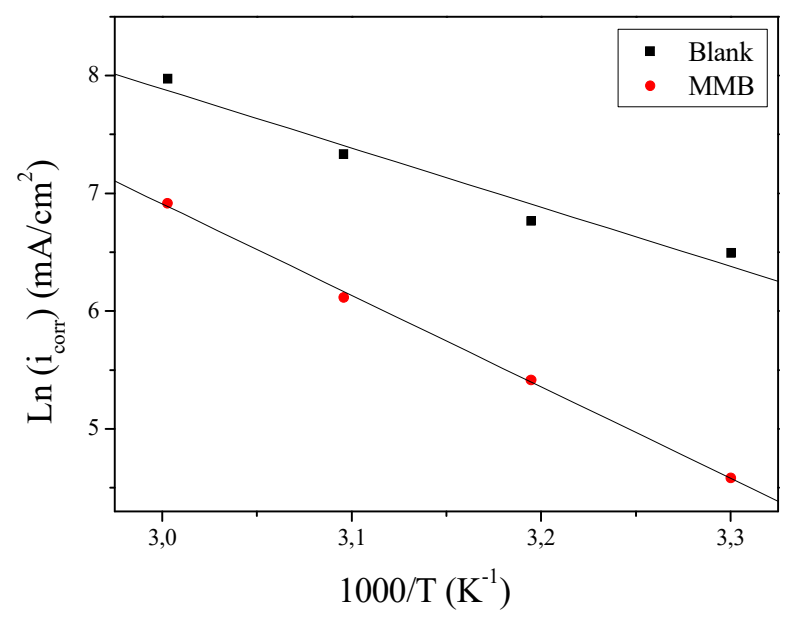

Figure 7. Arrhenius plot of $\mathrm{Ln} \mathrm{i}_{\text {corr }}$ versus $1000 / \mathrm{T}$ for carbon steel corrosion in $1 \mathrm{M} \mathrm{HCl}+$ $10^{-3} \mathrm{M}$ of MMB.

The linear regression coefficient was close to 1 , showing that carbon steel corrosion in $\mathrm{HCl} 1 \mathrm{M}$ can be interpreted using the kinetic model. The $\mathrm{E}_{\mathrm{a}}$ value calculated in an uninhibited solution $\left(41.74 \mathrm{~kJ} \mathrm{~mol}^{-1}\right)$ is in the same order of magnitude as previously described $[13,37]$. The obtained $E_{a}$ value, in the presence of the tested compound, is $64.62 \mathrm{~kJ} \mathrm{~mol}^{-1}$.

$\mathrm{E}_{\mathrm{a}}$ value, in the inhibitor presence, is more important than in its absence, indicating physical adsorption. The increase in activation energy explains the slight adsorption of the inhibitor onto the carbon steel surface with increasing temperatures $[38,39] . \Delta \mathrm{H}_{\mathrm{a}}$ and $\Delta \mathrm{S}_{\mathrm{a}}$ values evaluated from the slope $\left(\Delta \mathrm{H}_{\mathrm{a}} / \mathrm{R}\right)$ and the intercept of $\left[\operatorname{Ln}(\mathrm{R} / \mathrm{Nh})+\left(\Delta \mathrm{S}_{\mathrm{a}} / \mathrm{R}\right)\right]$ of the plots of $\operatorname{Ln}\left(\mathrm{i}_{\text {corr }} / \mathrm{T}\right)$ against $1 / \mathrm{T}$ (Fig. 8) are listed in Table 5. 


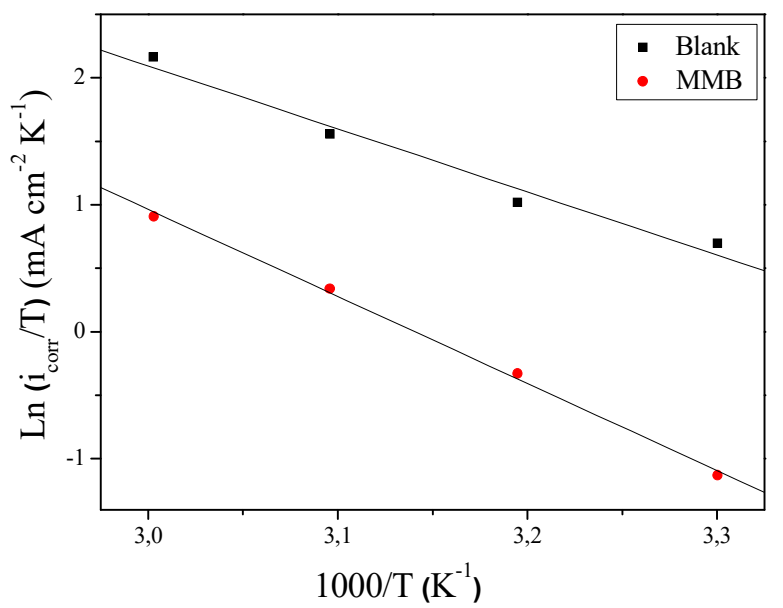

Figure 8. Variation of $\mathrm{Ln}\left(\mathrm{i}_{\text {corr }} / \mathrm{T}\right)$ versus $1000 / \mathrm{T}$ for blank and $1 \mathrm{M} \mathrm{HCl}+10^{-3} \mathrm{M}$ of MMB.

The positive signs of $\Delta \mathrm{H}_{\mathrm{a}}$ reflect that the $\mathrm{CS}$ corrosion process is of an endothermic nature. The data of Table 5 show that $\Delta \mathrm{H}_{\mathrm{a}}$ value is higher in the presence of the tested inhibitor $\left(61.85 \mathrm{~kJ} \mathrm{~mol}^{-1}\right)$ than that in its absence $(41.24 \mathrm{~kJ}$ $\left.\mathrm{mol}^{-1}\right) . \Delta \mathrm{S}_{\mathrm{a}}$ value is more positive in a $1 \mathrm{M} \mathrm{HCl}$ solution containing MMB than that of the uninhibited solution. Some researches interpreted this behavior by the replacement process of water molecules during the adsorption of the inhibitor molecule onto the electrode surface $[40,41]$.

Table 5. Corrosion kinetic parameters for carbon steel in $1 \mathrm{M} \mathrm{HCl}$, in the absence and presence of $10^{-3} \mathrm{M} \mathrm{MB}$.

\begin{tabular}{lccc}
\hline Medium & $\begin{array}{c}\mathbf{E}_{\mathbf{a}} \\
\left(\mathbf{k J ~ m o l}^{-\mathbf{1}}\right)\end{array}$ & $\begin{array}{c}\mathbf{\Delta} \mathbf{H}_{\mathbf{a}} \\
\left(\mathbf{k J} \mathbf{~ m o l}^{-\mathbf{1}}\right)\end{array}$ & $\begin{array}{c}\mathbf{\Delta} \mathbf{S}_{\mathbf{a}} \\
\left(\mathbf{J ~ m o l}^{-\mathbf{1}} \mathbf{K}^{-\mathbf{1}}\right)\end{array}$ \\
\hline Blank & 41.74 & 41.24 & -56.95 \\
MMB & 64.52 & 61.85 & -16.63 \\
\hline
\end{tabular}

\section{Conclusion}

2-[(5-methyl-isoxazol-3-yl)-methyl]-benzimidazole constitutes an effective class of corrosion inhibitor for carbon steel in $1 \mathrm{M} \mathrm{HCl}$. The efficiency increases with an increasing concentration, and maximum $\eta \%$ was attained at $87 \%$ at $10^{-3} \mathrm{M}$ concentration. Polarization study revealed that the tested compound is a mixed type inhibitor, inhibiting cathodic and anodic reactions by forming a protective film onto the metal surface. MMB adsorption on the carbon steel surface obeys the Langmuir adsorption isotherm. The adsorption occurs by chemical and physical interactions. The results obtained from PDP and EIS are in good agreement.

\section{Acknowlegdements}

This study was prepared with the support of the "RUDN University Program 5$100 "$. 


\section{References}

1. Tayebi H, Bourazmi H, Himmi B, et al. Der Pharm Lett. 2014;6:20-34.

2. Zarrok H, Salghi R, Zarrouk A, et al. Der Pharma Chem. 2012;4:407-16.

3. Shibli SMA, Saji VS. Corros Sci. 2005;47:2213-24.

4. Ahamad I, Quraishi MA. Corros Sci. 2009;51:2006-13.

5. Solmaza R, Altunbaş E, Kardaş G. Prot Met Phys Chem. 2001;47:264-71.

6. Solmaz R, Mert ME, Kardaş G, et al. Acta Phys Chim Sin. 2008;24:1185-91.

7. Chetouani A, Aouniti A. Corros Sci. 2003;45:1675-84.

8. Quraishi MA, Rawat J. Mater Chem Phys. 2002;73:118-22.

9. El-Maksoud SA. Corros. Sci. 2002;44:803-13.

10. Döner A, Şahin EA, Kardaş G, et al. Corros Sci. 20131;66:278-84.

11. Döner A, Kardaş G. Corros Sci. 2011;53:4223-32.

12. Yadav DK, Quraishi MA, Maiti B. Corros Sci. 2012;55:254-66.

13. El Aoufir Y, El Bakri Y, Lgaz H, et al. J Mater Environ Sci. 2017;8:3290-302.

14. Zarrok H, Zarrouk A, Salghi R, et al. Int J Electrochem Sci. 2013;8:6014-32.

15. Qian B, Hou B, Zheng M. Corros Sci. 2013;72:1-9.

16. Negm NA, Kandile NG, Badr EA, et al. Corros Sci. 2012;65:94-103.

17. Li X, Deng S, Fu H. Corros Sci. 2012;62:163-75.

18. El Azzaoui B, Rachid B, Doumbia ML, et al. Tetrahedron Lett. 2006;47:880710.

19. El Aoufir Y, Sebhaoui J, Lgaz H, et al. Mater. Environ. Sci. 2017;8:2161-73.

20. Tayebi H, Bourazmi H, Himmi B, et al. Der Pharm Chem. 2014;6:220-34.

21. Parveen M, Mobin M, Zehra S. RSC Adv. 2016;6:61235-48.

22. Hmamou DB, Salghi R, Zarrouk A, et al. J Environ Chem Eng. 2015;3:203141.

23. Bammou L, Belkhaouda M, Salghi R, et al. J Assoc Arab Univ Basic Appl Sci. 2014;16:83-90.

24. Krishnaveni K, Ravichandran JJ. Electroanal Chem. 2014;735:24-31.

25. Álvarez-Bustamante R, Negrón-Silva G, Abreu-Quijano M, et al. Electrochim. Acta 2009;54:5393-9.

26. Popova A, Christov M, Vasilev A. Corros Sci. 2007;49:3290-302.

27. Zarrouk A, Zarrok H, Ramli Y, et al. J Mol Liq. 2016;222:239-52.

28. Ahamad I, Prasad R, Quraishi MA. Corr Sci. 2010;52:1472-81.

29. Li X, Deng S, Xie X. J Taiwan Inst Chem Eng. 2014;45:1865-75.

30. Khaled KF. Electrochim Acta 2003;48:2493-503.

31. Avci G. Colloids Surf A. 2008;317:730-6.

32. Zarrouk A., Zarrok H, Salghi R., et al. J Chem Pharm Res. 2013;5:1482-91.

33. El Faydy M, Galai M, El Assyry A, et al. J Mol Liq. 2016;219:396-404.

34. Ali SA, Al-Muallem HA, Rahman SU, et al. Corros Sci. 2008;50:3070-7.

35. El Bakri Y, Boudalia M, Echihi S, et al. J Mater Environ Sci. 2017;8:378-88.

36. Zarrok H, Zarrouk A, Hammouti B, et al. Corros Sci. 2012;64:243-52.

37. Benabdellah M, Aouniti A, Dafali A, et al. Appl Surf Sci. 2006;252:8341-7.

38. Larabi L, Benali O, Harek Y. Mater Lett. 2007;61:3287-91.

39. Martinez S, Stern I. Appl Surf Sci. 2002;199:83-9.

40. Hammouti B, Zarrouk A, Al-Deyab SS, et al. Orient J Chem. 2011;27:23-31. 
41. Hmamou DB, Salghi R, Zarrouk A, et al. Res Chem Intermed. 2013;39:32913302. 